\title{
El tira y afloja por el control de la información política
}

Amparo López-Meri Universitat Jaume I

\section{Referencia de este artículo}

López-Meri, Amparo (2017). El tira y afloja por el control de la información política. En: adComunica. Revista Científica de Estrategias, Tendencias e Innovación en Comunicación, $\mathrm{n}^{0} 14$. Castellón: Asociación para el Desarrollo de la Comunicación adComunica y Universitat Jaume I, 277-278. DOI: http://dx.doi. org/10.6035/2174-0992.2017.14.17

CASERO-RIPOLLÉS, Andreu y LÓPEZ-RABADÁN, Pablo (eds.) (2016).

Periodistas y políticos en España.

Barcelona: Editorial UOC.

La complejidad de las relaciones entre periodistas y políticos constituye un tema central en el estudio de la comunicación política. El intento de la clase política por controlar la información, así como sus consecuencia, se ha abordado desde múltiples ópticas. El libro colectivo Periodistas y políticos en España, editado por Andreu Casero-Ripollés y Pablo López-Rabadán, sistematiza y complementa las aportaciones realizadas hasta el momento desde una perspectiva innovadora. En este sentido, su relevancia radica en dos factores, su novedoso enfoque y su solidez metodológica.

Respecto al primer factor, este libro es el primer estudio empírico sobre las relaciones entre periodistas y políticos centrado en el caso español. En cuanto a la metodología, se construye una visión global del fenómeno a partir de 45 entrevistas en profundidad, tanto a periodistas como a políticos, lo que supone un valor añadido en relación con estudios anteriores, que aporta mayor solvencia a los resultados. 
El vínculo entre periodistas y políticos se desglosa en ocho capítulos, desde dos puntos de vista. Por un lado, desde una óptica interna, para descifrar cómo influyen estas interacciones en la propia construcción de las noticias. Por otro lado, desde una óptica exterior, para entender cómo funcionan los mecanismos de control externo sobre la profesión periodística y el funcionamiento de la democracia.

En relación con la visión interna, el primer capítulo analiza la influencia de la amistad en las relaciones entre periodistas y políticos. Además de definirse los rasgos que caracterizan las relaciones interpersonales entre estos actores, se identifican los principales riesgos y beneficios que la afinidad personal supone para la cobertura informativa y el proceso de mediatización.

El segundo capítulo explora la progresiva influencia de los gabinetes de prensa y su impacto en la profesionalización de la comunicación política. El tercer capítulo aborda la lucha por el control de la agenda mediática. Se argumenta como los políticos tratan de influir en la selección de temas y enfoques, al tiempo que se evalúa el grado de autonomía que conservan los periodistas. Asimismo, el cuarto capítulo analiza la tendencia al infoentretenimineto y como la intimidad de los políticos se ha consolidado como una estrategia de comunicación válida que desdibuja los valores clásicos del periodismo político.

Por otro lado, desde una óptica externa, el quinto capítulo detalla las consecuencias de la politización del periodismo a través de dos fenómenos íntimamente vinculados a la pérdida de autonomía de los periodistas: el periodismo de declaraciones y los bloques electorales. El sexto capítulo revisa las dos dimensiones que adopta el control de la información política. Los periodistas ejercen el control mediante la fiscalización al poder, un mecanismo que encuentra respuesta en las presiones políticas a la prensa.

El capítulo séptimo se centra en la falta de independencia y pluralismo del periodismo, dos factores que preocupan a la ciudadanía. Así, recurriendo al barómetro del CIS, se contrasta la percepción de los periodistas y políticos, menos críticos respecto a la pérdida de estos valores, con la visión claramente negativa que manifiestan los ciudadanos. Por último, el capítulo octavo ahonda en los efectos del periodismo sobre el sistema democrático, analizando su influencia en la formación de la opinión pública, la toma de decisiones, el compromiso cívico y la desafección política.

En conclusión, el libro Periodistas y políticos en España, obra de 12 investigadores de tres universidades españolas, como resultado de un proyecto de investigación financiado por el Ministerio de Economía y Competitividad del Gobierno español, aporta una visión panorámica y plural de las relaciones entre periodistas y políticos, y de su impacto en la reconceptualización del periodismo político y los pilares del sistema democrático. La amplia muestra de entrevistas y puntos de vista que sustentan este trabajo avalan su utilidad tanto para estudiantes, como para periodistas y académicos. 


\section{El estudio de la producción como materia científica}

Javier Marzal Felici Universitat Jaume I

\section{Referencia de este artículo}

Marzal Felici, Javier (2017). El estudio de la producción como materia científica. En: adComunica. Revista Científica de Estrategias, Tendencias e Innovación en Comunicación, $\mathrm{n}^{0} 14$. Castellón: Asociación para el Desarrollo de la Comunicación adComunica y Universitat Jaume I, 279-282. DOI: http://dx.doi. org/10.6035/2174-0992.2017.14.18

TILLER TENREIRO, Carmen y PALACIO ARRANZ, Manuel (2016).

Producción y desarrollo de proyectos audiovisuales.

Madrid: Editorial Síntesis.

Para quienes llevamos ya bastantes años trabajando en la docencia e investigación en el grado (antes licenciatura) en Comunicación Audiovisual, nos es de sobras conocida la dificultad que encierra la formación y enseñanza de la producción audiovisual. Sin duda, el oficio de productor es uno de los perfiles profesionales más importantes y necesarios para los que capacita el seguimiento de estos estudios, si bien no es nada fácil alcanzar resultados óptimos, por diferentes motivos. 
Por un lado, se necesita tener una formación muy sólida en el campo audiovisual, tanto a nivel teórico -mediante la asimilación de conocimientos avanzados en tecnologías audiovisuales, teoría e historia de los medios audiovisuales (acreditando así una cultura audiovisual potente) y empresa-estructura del sector audiovisual- como a nivel práctico -a través del desarrollo de numerosos proyectos de producción-. Como hemos señalado en otro lugar, el trabajo del productor aúna «facetas artísticas y creativas que determinan la elección de las películas o series a producir, detecta qué tipo de producciones son las que pueden gozar de éxito entre el público, pero al mismo tiempo requiere de sólida formación empresarial, aplicada al campo del audiovisual, para hacer posible la gestión y organización de los recursos técnicos, humanos y financieros» (Marzal y Gómez Tarín, 2009: 14). Por otro lado, el productor, en cualquiera de sus modalidades (ejecutiva, delegada o como director de producción), debe tener una gran capacidad de liderazgo para gestionar y negociar, para detectar y obtener fuentes de financiación, para dirigir grupos humanos, para gestionar recursos técnicos, y debe ser alguien con gran sensibilidad y creatividad, capaz de interpretar en cada momento los gustos y tendencias dominantes del gran público o de públicos concretos.

Producción y desarrollo de proyectos audiovisuales sigue la estela de estudiosos como Cuevas (1976), Martín Proharam (1985), Jacoste (1996), Fernández Díez (1996) o Cabezón (1999). Hay que destacar que la literatura científica sobre el campo de la producción es bastante escasa en nuestro país, probablemente porque se trata de un ámbito de estudio de gran complejidad, que ha permanecido durante décadas en casi total oscuridad, alejado de la atención de la academia por tratarse de un espacio muy poco favorable a miradas intrusas (Pérez Perucha, 2009: 69-80).

En el primer capítulo, los autores nos ofrecen una extensa descripción del trabajo del productor ejecutivo, así como de las características de la dirección de los proyectos audiovisuales, ofreciendo un extenso examen, muy actualizado, de las principales vías de financiación cinematográfica, así como técnicas para la venta de proyectos, tan relevantes actualmente como el pitching. En el segundo capítulo, Ciller y Palacio abordan el estudio de la dirección de producción, de las tareas de organización y supervisión del proceso de producción, de una manera muy sistemática, clara y ordenada. En el capítulo tercero, los autores abordan el papel de los estudios de los públicos en las producciones cinematográficas, desde una perspectiva historiográfica, y mediante la exposición de las principales técnicas de estudio de los públicos, un apartado que nos parece especialmente original. A continuación, en el capítulo cuarto, se aborda el análisis de las campañas publicitarias en las producciones cinematográficas, en el que además de presentar un estudio de caso tan relevante, por su indudable valor histórico, como es el de la promoción de Bienvenido, Mister Marshall (Luis García Berlanga, 1953), se presenta un análisis de la composición social de la audiencia, un aspecto esencial para el trabajo del productor, que generalmente es obviado en este tipo de trabajos académicos. Finalmente, el capítulo quinto presenta el 
análisis de la gestión de proyectos audiovisuales, a través del estudio de cuatro casos muy relevantes en el contexto español como son La vida secreta de las palabras (Isabel Coixet, El Deseo S.A., 2005), La caja 507 (Enrique Urbizu, Iberrota Films, 2002), El asesinato de Carrero Blanco (Miguel Bardern, RTVE, 2009) y Silvio Rodríguez, Ojalá (Nico García, Catorce Comunicación, 2012). Así pues, se constata que estamos ante un estudio muy actualizado, que tiene el atractivo añadido de ofrecer información de primera mano de producciones reales, una perspectiva especialmente útil para la formación en este campo.

Hay que destacar, además, que Producción y desarrollo de proyectos audiovisuales surge en un momento en el que se percibe una revitalización del sector audiovisual en España, tras muchos años de fuerte crisis económica. En un contexto como el actual, ante un panorama cada vez más internacionalizado y global, es esencial contar con profesionales de la producción, capaces de liderar proyectos audiovisuales competitivos, cuando está en juego poder competir y hacer visible nuestra identidad cultural. Porque la existencia de productores competentes es condición de posibilidad de la propia industria audiovisual.

De este modo, podemos afirmar que Producción y desarrollo de proyectos audiovisuales es una obra relevante y muy necesaria en estos momentos, que viene a cubrir un evidente vacío en el ámbito de estudios sobre producción en el panorama académico actual. Y además, como sucede en materias de esta naturaleza que tienen que ver con la praxis profesional, buena parte de los contenidos de la obra son fruto de muchos años de investigación sobre la materia, así como de muchos años de experiencia profesional (acreditada) de los autores en el campo de la producción cinematográfica y televisiva, y de una constante y atenta mirada hacia el desarrollo de la profesión. Con frecuencia se olvida que en espacios académicos como éste es tan importante el rigor científico en el estudio de los procesos de producción como la observación sistemática y crítica de la práctica profesional. De este modo, Producción y desarrollo de proyectos audiovisuales se muestra como una obra que aúna la investigación académica, en un sentido clásico, con una clara voluntad por esclarecer y acercar al estudiante una materia fundamental para su formación como profesional del audiovisual. En este sentido, recomendamos la lectura y estudio de este libro, que destaca por su oportunidad y rigor, que edita la prestigiosa editorial Síntesis, que continua desarrollando una linea de publicaciones muy coherente y necesaria en la actualidad.

\section{Referencias}

Cabezón, L. A.; Gómez-Urdá, F. (1999). La producción cinematográfica. Madrid: Cátedra.

Cuevas Puente, A. [1976] (1999). Economía cinematográfica. La producción y el comercio de películas. Madrid: Imaginógrafo-EGEDA. 
Fernández Díez, F.; Martínez Abadía, J. (1996). La dirección de producción para cine y televisión. Barcelona: Paidós.

Jacoste Quesada, J. G. (1996). El productor cinematográfico. Madrid: Síntesis. Martín Proharam, M. A. (1988). La organización de la producción en el cine y la televisión. Madrid: Forja.

Marzal Felici, Javier y Gómez Tarín, Francisco Javier (eds.) (2009). El productor y la producción en la industria cinematográfica. Madrid: Editorial Complutense.

Pérez Perucha, Julio (2009). Materia oscura. En: Javier Marzal y Francisco J. Gómez. El productor y la producción en la industria cinemtográfica. Madrid: Editorial Complutense. 